\title{
Playtime at Robarts Library \\ Opening a family-friendly study space at the University of Toronto
}

f academic libraries are sincere about their

commitment to equity and inclusion, they must become more accessible for student parents - a large and underserved population whose members may also have other marginalized identities. Although accommodating children may seem to be outside the scope of academic libraries' mandate, if we are to fully support research and learning on campus, we must try to reduce obstacles for parenting students however we can, including welcoming their children into our libraries. To address this need, the University of Toronto Libraries recently opened Canada's first academic library family-friendly study space.

\section{Parenting students in the United States and Canada}

In the United States, 4.8 million undergraduate students are raising children, ${ }^{1}$ and there is a trend among U.S. institutions that cater to so-called nontraditional students to provide family-friendly library study spaces. Information about the number of students in Canada who are parents is not collected systematically, creating an invisible population. However, in the 2016 Canadian Graduate and Professional Student Survey, 49.3\% of respondents reported that family obligations were an obstacle to success, with $14.3 \%$ reporting that they were a major obstacle. ${ }^{2}$

According to Statistics Canada, Canadian women spend on average 50.1 hours per week on unpaid childcare, compared to
24.4 hours for men. ${ }^{3}$ Given that the burden of childcare primarily falls to women, lack of academic library support for parenting students disproportionately impacts women and has a negative effect on equitable access to library resources and services, as well as overall learning and research opportunities.

At the University of Toronto, parenting students expressed that they have had to choose their classes based on their childcare schedules and the type of course work involved. Group projects, for example, pose a challenge, because they may require students to arrange additional childcare. Accessing services that are only available in person, such as consultations with a librarian, can also be difficult to arrange, due to the challenges and expense of finding childcare.

\section{What are libraries doing?}

There are few services to support parenting students in academic libraries. In Canada, some universities have activity packs or child-friendly resources that children can use while their parents study. ${ }^{4,5}$ One has a corner in its basement where parents can bring their children, ${ }^{6}$ but there are no dedicated,

Jesse Carliner is communications and user services librarian, email: jesse.carliner@utoronto.ca, and Kyla Everall is user services librarian, email: kyla.everall@ utoronto.ca, at the University of Toronto Libraries

๑ 2019 Jesse Carliner and Kyla Everall 
secured study spaces available for parenting students. Such rooms are more commonly found in smaller American universities and colleges, as well as European academic libraries.

In particular, there is a noticeable gap among the libraries at top-ranked researchintensive universities. A review of the websites of the top 25 ARL libraries found only one mention of family-friendly space. ${ }^{7}$

\section{The University of Toronto context}

The University of Toronto is a public research-intensive university spread over three campuses in and around Toronto, Ontario, Canada. From 2017 to 2018 , the university had a total enrolment of 90,077 students. ${ }^{8}$ The University of Toronto Libraries system is the

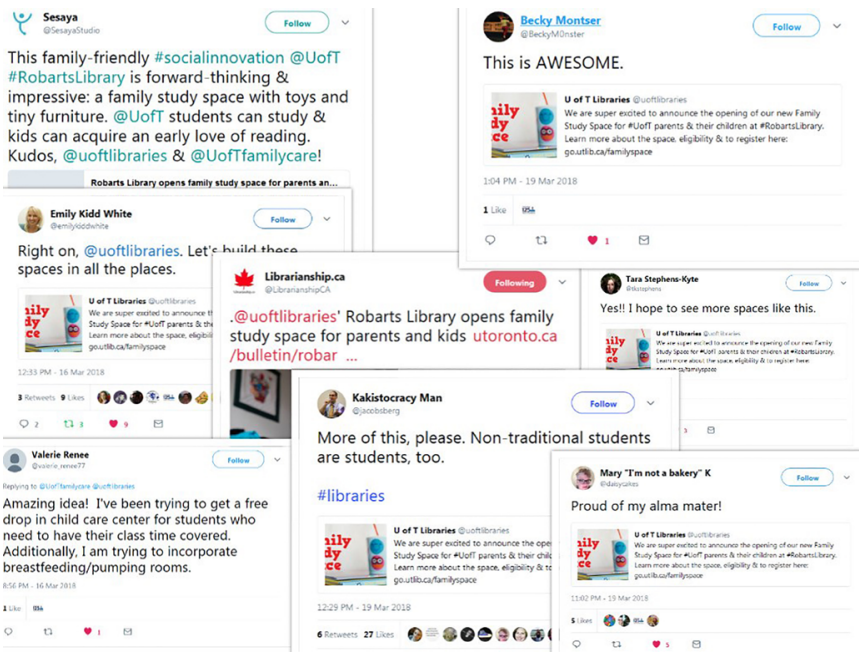

A selection of tweets responding to the opening of the Robarts Library Family Study Space. they were not welcome. When students did bring their children to the library, this would occasionally create conflict with other users over noise issues.

In the 2016 the University of Toronto Libraries LibQUAL+ survey, the library received a comment from a doctoral student requesting that the library provide a designated study space for students with children, citing many such spaces that they had seen in European universities.

According to The University of Toronto's Family Care Office, although the majority of graduate students at the University of Toronto are w o m e n, ${ }^{10}$ there were previously no academic services or spaces for parents who may have needed to bring their children to campus. Therefore, the University of Toronto Libraries delargest academic library in Canada and is ranked sixth among peer institutions in North America. ${ }^{9}$ The system consists of 44 libraries, with around 500 librarians and paraprofessional staff members.

Prior to the development of the Family Study Space, the John P. Robarts Library, the largest on campus and the primary social sciences and humanities library, had a policy allowing children 12 and under to accompany their parents to the closed stacks. The policy, however, was not posted publicly in the building or on the website. Under this policy, children had to be accompanied by a caregiver at all times. Although children were allowed in the library, the lack of a publicly posted policy may have created the impression that cided to address this need by developing a family-friendly study space in Robarts Library.

\section{Proposing the space}

In our large and complex library system, a family-friendly study space did not fit neatly within any one department's responsibilities or expertise. Developing the space would require cross-departmental collaboration for successful completion and operation. The project team comprised of staff from the library's public services departments, library facilities, and the university's Family Care Office. In order address the administrative challenges to developing the space, the project team proposed the project directly to the chief librarian who had set aside money 
from the operating budget to fund innovative ideas that did not fit within the library's organizational or budgetary structures.

In order to secure approval, the team needed to address concerns about liability and risk management regarding children in the library. The team reached out to the University of Toronto Family Care Office to ask them to serve in an advisory capacity on the project and to address concerns about risk management and liability. The Family Care Office intended user population, the space was developed in an enclosed room accessible only by key fob. Renovations to the room also included painting, upgraded tamper resistant electrical outlets, low emission carpet, and improvements to the room's ventilation system. As part of the project, nearby nursing facilities were upgraded.

To make the room comfortable and enjoyable for children, we provided child-sized furniture, toys, and a mat and

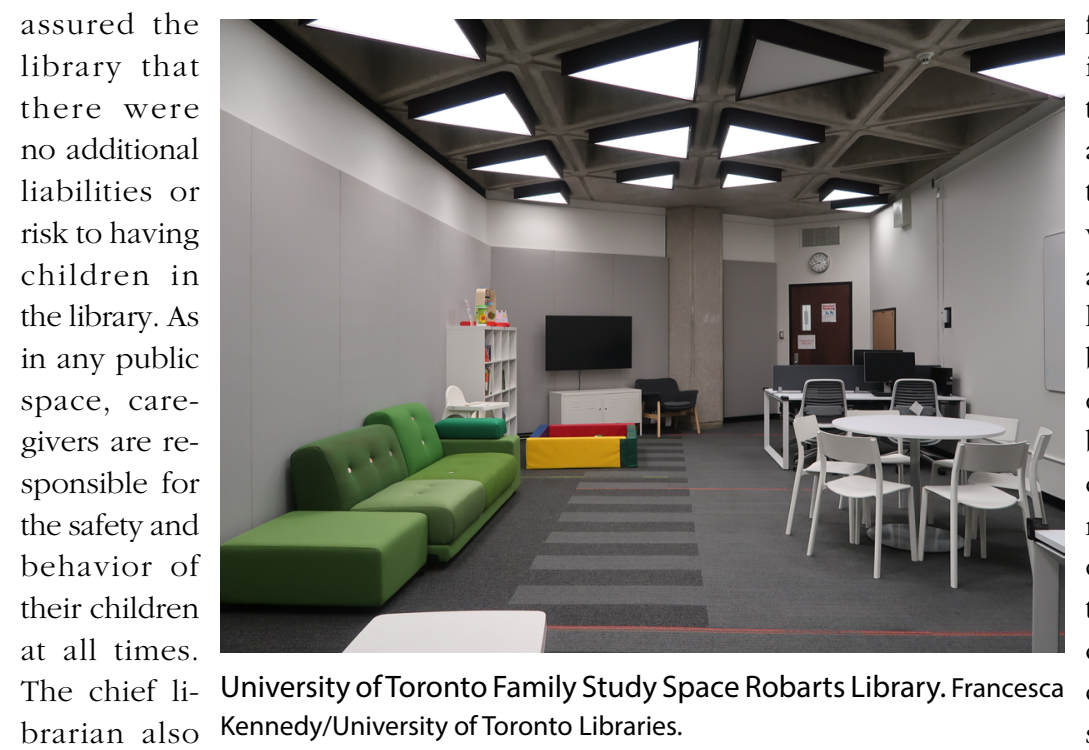
assured the library that no additional liabilities or risk to having children in the library. As space, caregivers are responsible for the safety and behavior of their children at all times. brarian also Kennedy/University of Toronto Libraries. consulted with the university administration, who were very enthusiastic in their support.

\section{Creating the space}

In designing the space, the team envisioned a room that would work for as many users and their children as possible- from small children, to older children, to users working alone or on group projects. Additionally, the room would ideally have the same features and technology that our other group study rooms and study spaces had.

With these considerations in mind, the room was furnished with presentation facilities, white boards, comfortable seating, and workstations. The space was also soundproofed to avoid noise complaints from other users. To ensure the safety of children and reserve the space for the tion in the catalog that is only accessible to users of the Family Study Space.

\section{Managing the space}

We developed the Family Study Space usage policies so that the space could be self-monitored, flexible, and operated in accordance with existing library and university policies. In the process of establishing the policies, we consulted with other libraries with similar spaces to learn from their experiences. We discovered that there were a wide variety of models for access and use. Some libraries required that their family room be reserved in advance, while others were first-come, first-served. We also found that there were some rooms that were child-friendly, but not reserved for the exclusive use of parenting students. 
The library decided that the room would be for the sole-use of the University of Toronto affiliated caregivers (students, staff, and faculty) with children 12 and under, who would be required to register for an access fob. The room would be available for use on a first-come, first-served basis at any time that the library was open. In order to avoid creating additional barriers to access, reservations are not required. The room policy emphasized that children were not to be left unattended in the room or anywhere in the library, and that caregivers are solely responsible for their children.

Since the room is unstaffed and selfmonitored, signage was posted to communicate room use policies, including how to report maintenance issues and deal with emergencies. Cleaning wipes are available in the room to encourage users to clean up small spills on tables and desks.

Registration and fob access is managed by the department responsible for the graduate student carrels in the library. The carrel office processes the registration applications, confirms eligibility status and distributes the fobs. Users can register online at any time of the year.

We will conduct both formal and informal assessment of the space to make service improvements and evaluate the success of the room. Starting in the next academic year, we will offer research consultations with librarians in the space, in response to feedback that consultations can be difficult to schedule for parenting students.

\section{Promoting the space}

The library opened the space with a reception, and promoted it on social media as well as through print marketing materials at the library and around the university. The central message was that the library welcomes the children of our academic community members. This message and the news that there was a space designed especially for children and their caregivers resonated across the university, Canada, and internationally.

The announcement generated a great deal of discussion, positive feedback, and engagement on social media and in university and local news outlets. The response indicated considerable interest and demand for family friendly services at academic libraries and within higher education. Many former students, both from the University of Toronto and elsewhere, commented via social media about how a family-friendly study space would have made a significant difference for them while they were in school. Current students from other universities engaged with their school social media channels to ask for a similar space. The creation of the Robarts Library Family Study Space also started a dialogue within the Canadian library and higher education communities about students with children and what can be done to support them. More than 100 registrations have been received so far for the end of the spring and start of the summer academic terms, and even more registrations are anticipated with the start of the next academic year.

\section{Conclusion}

According to the University of Toronto's Family Care Office, student parents usually face three main obstacles while pursuing their post-secondary education: childcare, financial issues, and time management. Family-friendly study spaces in academic libraries address all three of these concerns for parenting students, while also supporting the research, teaching, and learning missions of higher education institutions.

The library received a comment from a user who called the Family Study Space, a "very important and much needed space as child care is so scarce and expensive. I can bring my kid and get some work done." Family-friendly study spaces unequivo-

(continues on page 111) 
research libraries have a social responsibility to preserve and present cultural heritage collections for the benefit of the peoples who created and donated the contents, keeping in mind the originator's purpose and intent. It is our privilege to work with them and to creatively share their stories as appropriate.

\section{Notes}

1. This article was adapted in part from a talk given September 28, 2017, at Oberlin College, where I served as a consultant for their Andrew W. Mellon Foundation planning grant, Strengthening Collaborations Between Academic Art Museums and Libraries.

2. Irene Herold, July 2016, "Leveraging Cultural Collections," Library Issues, 36(6).
3. Retrieved October 9, 2017, from http:// www.unesco.org/new/en/cairo/culture /tangible-cultural-heritage/.

4. Retrieved October 9, 2017, from http:// www.cultureindevelopment.nl/cultural _heritage/what_is_cultural_heritage.

5. Simon Thurley, "Into the future, Our strategy for 2005-2010," in Conservation Bulletin [English Heritage], 2005 (49).

6. Herold, "Leveraging Cultural Collections," 2-3.

7. See https://www.keene.edu/news /stories/detail/1345061446198/.

8. See http://library.manoa.hawaii.edu /departments/archives/mss/aja/.

9. See https://commons.keene.edu /handle/20.500.12088/91. n

("Playtime at Robarts Library," continues from page 103)

cally communicate the message that you can be a student and a parent. Welcoming the whole student to the library and the university increases inclusion. Creating family-friendly spaces helps libraries further their mission to provide equitable access to information for their communities.

\section{Notes}

1. Elizabeth Noll, Lindsey Reichlin, Barbara Gault, College Students with Children: National and Regional Profiles (Washington, D.C.: Institute for Women's Policy Research, 2017), 1, https://iwpr.org/wp-content /uploads/2017/02/C451-5.pdf.

2. Canadian Graduate and Professional Student Survey-2016: Summary Report, All Respondents (Canadian Associations for Graduate Students, 2016), 11, www. cags.ca/documents/cgpss/2016/NATIONAL _CGPSS_2016_REPORT_ALL.pdf.

3. Statistics Canada, "Time spent on unpaid care of a child in the household, by working arrangement and age of youngest child, Canada, 2010," table 6 in Women in Canada: A Gender-Based Statistical Report, Statistics Canada Catalogue no. 89-503-X (Jul. 2011), https://www150.statcan.gc.ca /n1/pub/89-503-x/2010001/article/11546/tbl /tbl006-eng.htm.

4. Sonya, "Introducing the RULA Busy Box!," Ryerson University Library and Archives, accessed July 6, 2018, https://library.ryerson.ca/ blog/2018/03/introducing-the-rula-busy-box/.

5. "PGSS Family Collection," McGill Library, accessed July 6, 2018, https://www. mcgill.ca/library/channels/news/pgss-family -collection-230976.

6. "Library Supports and Reference Assistance," University of Alberta, accessed July 6, 2018, https://www.ualberta.ca/augustana /services/aso/programs-and-services/library.

7. "Family Friendly Spaces Campus Guidelines," University of Washington Bothell, accessed July 6, 2018, www.uwb.edu /administration-planning/auxiliary-services /family-friendly-space.

8. "Quick Facts," University of Toronto, accessed July 6, 2018, https://www.utoronto. ca/about-u-of-t/quick-facts.

9. https://www.arlstatistics.org/analytics.

10. University of Toronto, Facts and Figures 2017 (Toronto: University of Toronto, n.d.): 35. https://www.utoronto.ca/sites /default/files/Facts\%20\%26\%20Figures \%202017\%20online\%20version.pdf. „ 